\title{
Progress in Clinical Neurosciences: Evidence Based Care in the Neurosciences
}

\author{
Samuel Wiebe and Bart Demaerschalk
}

\begin{abstract}
We examine the relevance of Evidence Based Care (EBC) to the field of clinical neurosciences, with particular emphasis on feasible methods of implementing EBC in clinical practice. By using pre-appraised EBC summaries, busy clinicians can move toward EBC without engaging in the laborious process of searching and critically appraising the literature. After reviewing the neurological content, accessibility and ease of use of current sources of EBC summaries, we find them substantially lacking in coverage of the neurosciences, and therefore of limited use to clinicians in this field. We emphasize a particular type of EBC summary, the critically appraised topic, and comment on its usefulness and limitations as a tool to assist clinical decision-making in the neurosciences. Finally, we propose that a collection of easily accessible, good quality, peer reviewed critically appraised topics, covering a breadth of relevant topics, is a reasonable way of moving toward EBC in the clinical neurosciences.
\end{abstract}

RÉSUMÉ: Soins basés sur des preuves en neurosciences. Nous examinons la pertinence des soins basés sur des preuves (evidence-based care - EBC) en neurosciences cliniques, en mettant l'accent sur des méthodes concrètes pour appliquer l'EBC en pratique clinique. Le clinicien occupé peut instaurer l'application de l'EBC en utilisant des sommaires d'EBC préévalués, sans avoir à faire lui-même le processus laborieux de recherche et de critique de la littérature. Après avoir révisé le contenu neurologique, l'accessibilité et la facilité d'utilisation de sources à jour de sommaires d'EBC, nous constatons que la couverture dans le domaine des neurosciences est très déficiente et donc d'utilité limitée pour le clinicien travaillant dans ce domaine. Nous mettons l'accent sur un type particulier de sommaire d'EBC, le critically appraised topic (CAT), et nous commentons son utilité et ses limites comme outil d'aide à la décision clinique en neurosciences. Finalement, nous proposons qu'un recueil de CATs facilement accessibles, de bonne qualité et révisés par des pairs, couvrant une gamme de sujets pertinents, est une façon raisonnable d'instaurer l'EBC en neurosciences cliniques.

Can. J. Neurol. Sci. 2002; 29: 115-119

Although much has been written about the principles of and rationale for evidence based care (EBC) in general, there has been little discussion about its application in the clinical neurosciences. The discussion is relevant for several reasons. First, this is a vast field, encompassing specialized medical, surgical, paediatric and allied health disciplines, all of which have their own sources of scientific information. Second, specialized clinicians tend to read journals in their own specialty ${ }^{1-3}$ and are less likely to read general medical journals, the main forum for EBC publications. Third, the scope of the clinical neurosciences has broadened to include not only a rich description of clinical phenomena, but also a large array of diagnostic and therapeutic interventions. The literature in neurosciences has exploded. A quick literature search through PubMed, using the major categories of neurological disorders as $\mathrm{MeSH}$ headings and limiting to publication of type "randomized controlled trials (RCTs)" is revealing. In the last decade alone, nearly 3,000 RCTs of therapeutic interventions have been published in the main neurological areas, excluding pain, in which over 6,000 RCTs have been published during this time. At last count, nine of the Cochrane collaboration review groups and 97 of the completed meta-analyses on therapy pertain to the neurosciences, with many more underway (www.cochranelibrary. $\mathrm{com} /$ ). At least a similar number of publications can be expected

From the Department of Clinical Neurological Sciences, University of Western Ontario, London, Ontario, Canada (SW), and the Stroke Centre, Mayo Clinic Scottsdale, Scottsdale, Arizona, USA(BD).

ReCeived SePtember 21, 2001. Acceptedin final form December 13, 2001. Reprint requests to: Samuel Wiebe, London Health Sciences Centre, University Campus, 339 Windermere Rd., London, Ontario, Canada N6A5A5 
for diagnostic interventions and this does not include the bulk of the publications, such as uncontrolled studies and laboratory medicine. Fourth, efforts to move toward EBC in the neurosciences are insufficient, as confirmed by our extensive Internet searches, consulting evidence based discussion lists (evidence-based-health@jiscmail.ac.uk), and direct communication with EBC experts. Some examples include the American Academy of Neurology's annual meeting course and a brief course for residents, as well as an established EBC curriculum in the neurology training programme at the University of Western Ontario. ${ }^{4}$ Therefore, it is useful to consider approaches that may help clinicians in the neurosciences move toward EBC.

\section{The Role OF EBC}

It has been said that "the central job of doctors is to meet the needs of patients by drawing on the knowledge accumulated by medicine over 5,000 years". 5 Medical information has a short doubling time of approximately 10 years and medical knowledge increases fourfold during a medical professional life. Yet, only about $18 \%$ of published articles are scientifically sound and clinicians need to sort useful from useless literature. ${ }^{6}$ This makes it very difficult for clinicians to keep updated. ${ }^{7}$ It is estimated that one would have to read 19 journal articles a day, 365 days a year in order to keep abreast of relevant knowledge in one's own area. ${ }^{8}$ Neurologists, neurosurgeons, and allied health clinicians trying to keep up with the best evidence are unlikely to succeed. As shown repeatedly in other specialties, our knowledge of the best evidence, about even basic problems, deteriorates over time ${ }^{9}$ and there is every reason to expect that clinicians in the neurosciences face the same challenge. Unfortunately, traditional continuous medical education and classroom teaching have little or no long lasting impact on clinicians' performance. ${ }^{10-12}$ Resorting to traditional, nonsystematic reviews and recent book chapters does not get us much further. For example, Oxman and Guyatt $^{13}$ showed that traditional reviews vary widely in their scientific merit, content and emphasis even within the same topic. Also, it has been shown that these sources can be outdated by approximately 10 years. ${ }^{14}$ Because EBC entails accessing, appraising and applying the best evidence to the care of individual patients, it presents clinicians with a reasonable framework to deal with clinical entropy. ${ }^{15}$ Evidence based care is not a substitute for the art of medicine; instead, it aims at enabling clinicians to combine optimum clinical skills and acumen with the best external evidence.

\section{Allclinicians Can PRaCtice eVIDEnCE baSed CARE}

Our aim is not to elaborate on the basic principles of EBC but rather to explore ways in which all clinicians in the neurosciences can benefit from this systematic approach. The principles of EBC have been amply described by Sackett and others $^{15,16}$ and readers can also find a full description of the principles and practice of EBC in the resources listed in Table 1. Briefly, EBC entails the following steps:

1) stating the clinical problem at hand in the form of a defined, answerable question;

2) efficiently searching the literature for the best evidence;

3) critically appraising the evidence for its validity and usefulness; and
4) applying the evidence in the context of the patients' circumstances and values.

Depending on the clinical question asked and on the expertise of the individuals, the entire process takes between one and two hours per question at the University of Western Ontario's Evidence Based Neurology teaching sessions, where expert guidance is available. ${ }^{17}$

Undoubtedly, the process is laborious and requires special skills that not all clinicians are willing or able to learn and implement. A survey of faculty and trainees in a clinical neurosciences programme in Canada showed that both groups considered EBC as highly relevant, but their self-rated proficiency in the principles of EBC was low. ${ }^{18}$ Similarly, a survey of general practitioners in the UK revealed that EBC was

Table 1: Additional Resources

\section{EBC WEBSITES}

www.shef.ac.uk/ scharr/ir/netting/ (the most comprehensive catalogue of EBC websites and resources)

www.cche.net/principles/main.asp (Canadian centres for health evidence, promising site under construction)

www.cebm.jr2.ox.ac.uk/ (EBC at Oxford, useful tools and links)

http://hiru.mcmaster.ca/ (EBC at McMaster University, useful tools and links)

http://www.med.ualberta.ca/ebm/ebm.htm (EBC at University of Alberta, Canada. Useful tools and links)

\section{USERS' GUIDES TO THE MEDICAL LITERATURE (JAMA SERIES)}

www.cche.net/principles/main.asp

\section{Clinicalpractice guidelines}

www.cma.ca/cpgs/ (Canadian practice guidelines) www.guideline.gov/index.asp (US National guideline clearinghouse)

\section{Critically aPPRAised topics (CATs)}

www.journalclub.org/ (Internal medicine pre-appraised topics with some neurological content)

http://dfcm19.med.utoronto.ca/twhdfcm/evans.htm (Family Medicine pre-appraised topics with some neurological content)

http://ahsn.lhsc.on.ca/cat/ (Critical care medicine pre-appraised topics with some neurological content)

www.med.unc.edu/medicine/edursrc/!catlist.htm (University of North Carolina, general medicine pre-appraised topics with some neurological content)

http://www.urmc.rochester.edu/medicine/res/CATS/neuro.html (University of Rochester, general medicine pre-appraised topics with some neurological content)

http://depts.washington.edu/pedebm/topic/index.html (University of Washington, general medicine pre-appraised topics with some neurological content)

\section{Books}

Sackett DL, Straus SE, Richardson WS, Rosenberg W, Haynes RB. Evidence-Based Medicine: How to Practice and Teach EBM. 2nd ed. Edinburgh: Churchill Livingstone, 2000.

Sackett DL, Haynes RB, Guyatt GH, Tugwell P. Clinical Epidemiology. A Basic Science for Clinical Medicine. 2nd ed. Boston/Toronto: Little, Brown and Co., 1991. 
Table 2: Criteria for selecting articles that are most likely to provide valid results.

\section{Electronic permission not granted}

an important tool, but the overwhelming majority felt that implementing the arduous four steps of EBC "from scratch" was not the best way to deal with the problem in busy clinical practice. Instead they favoured using EBC summaries produced by others as the best way of implementing the best external evidence. ${ }^{19}$ Guyatt et a ${ }^{20}$ commented on similar findings among trainees at McMaster University, emphasizing that a basic understanding of EBC principles enables all clinicians (including those less inclined to engage in the full $\mathrm{EBC}$ exercise) to search for and apply EBC summaries effectively.

Commentators recognize that clinicians practice EBC in three different modes, shifting among these modes as needed. ${ }^{21}$ "Doers" of EBC (often those with training in EBC principles) take on the entire EBC process as described above; "users" of EBC tap on pre-appraised EBC summaries produced by others; and "replicators" of EBC resort to distilled information from respected opinion leaders. ${ }^{21}$ By observing trainees in the evidence based neurology programme at the University of Western Ontario, and participating as facilitators in numerous EBC workshops for neurologists, we confirm Guyatt et al's ${ }^{20}$ and Strauss et al's ${ }^{21}$ observations. All clinicians benefit from EBC skills, e.g., knowing what determines whether a study is valid or not (Table 2). However, busy clinicians prefer pre-appraised EBC summaries produced by others as the best way to implement $\mathrm{EBC}$, and they need to know where to find and how to apply these summaries.

\section{EBC SUMMARIES FOR THE NEUROSCIENCES}

The advantages of consulting pre-appraised EBC summaries are readily apparent. Clinicians are spared the tasks of searching the literature, choosing the studies, critically appraising them and extracting clinically meaningful information. Instead, by applying methodological filters and pre-appraising the evidence, these resources allow busy clinicians to quickly read a one- or two-page synopsis describing the clinical topic, the nature and quality of the evidence and the results. Furthermore, finding the relevant EBC summaries is typically fast and easy. For example, searching Best Evidence ${ }^{\circledR}$ or the Cochrane Library ${ }^{\circledR}$, two typical sources of EBC summaries, takes no more that two minutes, on average. Summaries can range in comprehensiveness from a digest of a single article to a full meta-analysis of many studies with an accompanying structured abstract. The main sources of EBC summaries are:

\section{The Cochrane Library®}

This most comprehensive resource contains three sections that are useful for EBC pertaining to therapy, prevention, and quality improvement. The section on full-text meta-analyses is probably the most important and clinically useful. Its neurological content is already substantial and it is growing, as shown by the following Cochrane Review Groups that produce EBC summaries related to the neurosciences: 1) Stroke, 2) Neuromuscular Disease, 3) Spinal Disorders, 4) Pain, Palliative, and Supportive Care, 5) Movement Disorders, 6) Dementia and Cognitive Impairment, 7) Epilepsy, 8) Injury, and 9) Multiple Sclerosis. A second section includes abstracts, of meta-analyses produced by other research groups or individuals. The third section is the most comprehensive database of RCTs. In summary, this is a useful and promising source of EBM summaries for the neurosciences, but at this stage lacks sufficient coverage of this area. The Cochrane Library ${ }^{\circledR}$ can be purchased from the Canadian Medical Association (www.cma.ca) and from Update Software Inc. (www.cochranelibrary.com/).

\section{Best Evidence CD-ROM ${ }^{\circledR}$}

This is a compilation of the articles from two evidence-based medicine journals, the ACP Journal Club and Evidence-Based 
Medicine. Its entries consist of easy to read, two-page EBC summaries with commentaries from experts. It is easy to search and it also contains useful additional information such as an EBC glossary and clinical practice guidelines. It contains several thousand EBC summaries of original articles and systematic reviews published in over 150 clinical journals. The information is frequently reviewed and updated. Each article meets stringent methodological requirements, and has clinically relevant results. The main drawback is its sparse neurological content, which is limited to the commonest problems. Best Evidence ${ }^{\circledR}$ can be purchased from the Canadian Medical Association (www.cma.ca) and the American College of Physicians (www.acponline.org/catalog/electronic).

\section{Evidence-Based Medicine Reviews (EBMR)}

This wide-ranging resource can be purchased from Ovid Technologies (www.ovid.com). It combines several electronic databases, including the Cochrane Database of Systematic Reviews, Best Evidence, Evidence-Based Mental Health, Evidence-Based Nursing, Cancerlit, Healthstar, Aidsline, Bioethicsline, and MEDLINE, plus links to over 200 full text journals. The reviews are all prepared according to explicit principles and procedures for sorting and appraising evidence according to quality and content.

\section{Clinical Evidence ${ }^{\circledR}$}

Published by the British Medical Journal (www.bmjpg.com/) and the American College of Physicians (www.acponline.com), Clinical Evidence is available by subscription. It is a compilation of EBC summaries with commentary from an expert. The format is that of a book with frequent updates. Its focus on general medicine limits the neurological content and therefore its usefulness for clinicians in the neurosciences.

\section{Bandolier}

This free electronic journal is a compilation of EBC summaries, meta-analyses and commentaries, and is an excellent resource (www.jr2.ox.ac.uk:80/Bandolier/). Its neurosciences content, particularly in the area of pain, is better than average for a general medicine journal, but still insufficient. It also contains useful, clinician-friendly notes on interpretation of clinical research. Searching is simple and summaries can be downloaded or printed. Check, for example, Bandolier's EBC summaries on pain, acute migraine therapy, new antiepileptic drugs and stroke prevention in atrial fibrillation.

\section{Health Technology Assessment}

Produced by the National Health Service's Office of Health Technology Assessment in the United Kingdom, this site (www.hta.nhsweb.nhs.uk/) contains a small number of metaanalyses and cost-effectiveness analyses with EBC summaries pertaining to the neurosciences and encompassing therapy and diagnosis. Access to this excellent resource is still free, and full text PDF files can be downloaded or printed.

\section{Clinical Practice Guidelines}

Table 1 lists a sample of freely accessible guidelines. When adequately executed, these pre-appraised evidence summaries can be very useful, as they contain practice recommendations that incorporate other elements of clinical decision making, such as cost and patients' values. The main criteria for judging their usefulness are listed in Table 2. As with other resources, the main limitation is their meagre neurological content. However, searching these compilations is fast and easy and it may prove helpful.

\section{Critically Appraised Topics (CATs)}

A CAT is a concise one- to two-page summary of the first three steps of the EBC process for a clinical question, as described above under "All clinicians can practice EBC." Thus, it contains a focused clinical question, results of the literature search, and a synopsis of the critically appraised evidence expressed in clinically meaningful terms or clinical bottom lines. Critically appraised topics were originally created by internal medicine fellows at McMaster University "as a means for sharpening their critical appraisal skills and improving their abilities as bedside teachers of EBM" (http://cebm.jr2.ox.ac.uk/docs/cats/catabout.html). Because CATs are concise and portable they have been incorporated into several undergraduate and postgraduate training programmes. However, because CATs are patient-based and evidence-based they are also helpful at every stage of a clinician's learning experience as a self-teaching tool that integrates evidence with clinical expertise to make patient-care decisions. Critically appraised topics are therefore ideally suited for "users" of EBC who are unable to engage in the entire EBC process. Several CAT "banks" have been created (Table 1), but because none focuses on the neurosciences, their neurological content is limited. The University of Western Ontario's evidence based neurology training programme generates two neurological CATs per month, whose themes encompass therapy, diagnosis, prognosis, harm, the neurological examination, as well as integrative studies (Table 2), ${ }^{17}$ and other training programmes and clinicians may be producing their own. However, there is no mechanism at present to ensure widespread availability of these EBC summaries.

Critically appraised topics have some limitations. First, because they are often posted without peer review, individual CATs can be wrong, by virtue of not including the appropriate evidence, or having errors of fact, calculation, or interpretation of the data. Therefore, users are encouraged to give preference to CATs that have undergone peer review. Second, although some CATs summarize meta-analyses or similar integrative studies, many are the results of a quick search for a single article that addresses the clinical question at hand. Thus, they may portray only a fragment of the evidence. Third, CATs are not intended to avoid all journal reading. Although CATs can cover a broad range of clinical research, e.g., diagnostic, qualitative, descriptive, etc., clinicians still need to read journals judiciously for topics that are dealt with incompletely or not at all in CATs. Fourth, CATs become obsolete as soon as new evidence appears and they need to be updated accordingly. A good CAT should allow users to have a glimpse into the scope of the evidence, the quality of the evidence, the results and their clinical meaning, and their shelf life. The following elements help define a good CAT and can assist readers to determine its validity and currency.

1) The clinical question is clearly stated,

2) the literature search strategy and findings are described,

3) there is a concise description of the studies included, 
4) raw data (actual numbers) are presented in addition to the summary calculations (e.g., absolute risk reduction, number needed to treat, etc.),

5) there is a declarative answer to the clinical question, and

6) it contains a date of creation to determine its obsolescence.

Limitations not withstanding, CATs can be efficient EBC summaries that provide a summary of the quality and nature of the available evidence and, if necessary, they can be used as a starting point to seek and appraise updates in the relevant areas.

There is a dearth of neurological CATs and clinicians in the neurosciences striving to implement $\mathrm{EBC}$ would benefit from a large collection of widely available, good quality CATs. This issue of the Canadian Journal of Neurological Sciences contains one neuro-CAT on prognosis of a first unprovoked seizure. It contains a complete description of the EBC process that was used in the production of the CAT, as well as the one-page CAT for quick reference.

\section{Conclusions}

We conclude that EBC is highly relevant to clinicians in the neurosciences. By using pre-appraised EBC summaries, busy clinicians who want to implement EBC can do so without engaging in the laborious process of searching and critically appraising the literature. After reviewing the neurological content, accessibility and usefulness of several sources of EBC summaries, we conclude that coverage of the neurosciences is generally unsatisfactory in existing sources. There is a need for large collections of good quality, peer-reviewed, EBC neurological summaries, such as CATs. We review the usefulness and limitations of CATs as tools to assist clinical decisionmaking and suggest a checklist to assess their validity. Finally, to be clinically useful, EBC summaries need to be published in ways that ensure ready and free access by clinicians in all fields of the neurosciences.

\section{REFERENCES}

1. Saint S, Christakis DA, Saha S, et al. Journal reading habits of internists. J Gen Intern Med 2000; 15: 881-884.

2. Vickery CE, Cotugna N. Journal reading habits of dietitians. J Am Diet Assoc 1992; 92: 1510-1512.

3. Schein M, Paladugu R, Sutija VG, Wise L. What American surgeons read: a survey of a thousand Fellows of the American College of Surgeons. Curr Surg 2000; 57: 252-258.
4. Demaerschalk B, Wiebe S, Jenkins M. Evaluating the impact of an evidence based medicine curriculum in a neurology training programme. Can J Neurol Sci 1999; 26: S52

5. Smith R. What clinical information do doctors need? Br Med J 1996; 313: 1062-1068.

6. Smith R. Where is the wisdom...? Br Med J 1991; 303: 798-799.

7. Wyatt J. Use and sources of medical knowledge. Lancet 1991; 338: 1368-1373.

8. Sackett DL, Richardson WS, Rosenberg W, Haynes RB. Introduction: On the need for evidence-based medicine. In: Sackett DL, Richardson WS, Rosenberg W, Haynes RB (eds). Evidence-based Medicine: How to Practice \& Teach EBM. New York: Churchill Livingstone, 1997: 1-20.

9. Ramsey PG, Carline JD, Inui TS, et al. Changes over time in the knowledge base of practicing internists. JAMA1991; 266: 11031107.

10. Sibley JC, Sackett DL, Neufeld V, et al. A randomized trial of continuing medical education. N Engl J Med 1982; 306: 511-515.

11. Evans CE, Haynes RB, Birkett NJ, et al. Does a mailed continuing education program improve physician performance? Results of a randomized trial in antihypertensive care. JAMA1986; 255: 501504.

12. Davis DA, Thomson MA, Oxman AD, Haynes RB. Changing physician performance: a systematic review of the effect of continuing medical education strategies. JAMA1995; 274: 700705.

13. Oxman AD, Guyatt GH. The science of reviewing research. Ann N Y Acad Sci 1993; 703: 125-133.

14. Antman EM, Lau J, Kupelnick B, Mosteller F, Chalmers TC. A comparison of results of meta-analyses of randomized control trials and recommendations of clinical experts. Treatments for myocardial infarction. JAMA1992; 268: 240-248.

15. Sackett DL, Rosenberg WM, Gray JA, Haynes RB, Richardson WS. Evidence based medicine: what it is and what it isn't [editorial]. Br Med J 1996; 312: 71-72.

16. Davidoff F, Haynes B, Sackett D, Smith R. Evidence based medicine [editorial; comment]. Br Med J 1995; 310: 1085-1086.

17. Wiebe S, Demaerschalk B, Jenkins M. Development and introduction of a formal evidence based medicine curriculum in a neurology training programme. Can J Neurol Sci 1999; 26: S23.

18. Demaerschalk B, Wiebe S. Evaluating the relevance of evidence based medicine in a neurology residence programme. Can $\mathrm{J}$ Neurol Sci 1998; 25: S79.

19. McColl A, Smith H, White P, Field J. General practitioners' perceptions of the route to evidence based medicine: a questionnaire survey. Br Med J 1998; 316: 361-365.

20. Guyatt GH, Meade MO, Jaeschke RZ, Cook DJ, Haynes RB. Practitioners of evidence based care. Not all clinicians need to appraise evidence from scratch but all need some skills. Br Med J 2000; 320: 954-955.

21. Straus SE, McAlister FA. Evidence-based medicine: a commentary on common criticisms. CMAJ 2000; 163: 837-841. 